\title{
The Application of Schema Theory in the Teaching of English Reading in Senior High Schools
}

\section{Ying Ma}

School of Foreign Languages, China West Normal University, Nanchong, Sichuan, China

\begin{abstract}
In English learning, good reading ability is very important. In recent years, the scores of students' reading ability in the college entrance examination have also increased. However, in many cases, even though students can understand the vocabulary and syntax of the text, they still cannot correctly grasp the main point of the text. They are easily immersed in the details of the text and cannot grasp the key content. There is a certain relationship between English reading and schema theory. The more complete a student's schema, the more targeted and efficient the processing of text materials. Therefore, high school English teachers should make full use of schema theory to improve teaching strategies, and focus on the development of students' schemata, so as to enhance students' English reading ability and information processing ability.
\end{abstract}

Key words: schema theory; English reading; English teaching

English reading is a "hard bone" for many senior high school students. Many students have insufficient vocabulary or lack of cultural background knowledge, which makes them very confused in the process of reading. Though some students know every word, it's still difficult for them to grasp the main idea or understanding the sentence. The reason is that their knowledge reservation is not sufficient. Many teachers are also aware of this problem. However, in the real teaching process, they still cannot systematically help students build knowledge networks and teach students efficient reading strategies. High school students are relatively mature in all aspects and have the ability to receive systematic reading training. On the basis of schema theory and combining the three major modes of English reading, this paper proposes strategies for teaching high school English reading.

\section{Definition of Reading}

Reading is a basic language skill. There are many different kinds of reading activities in real life. Eddie Williams (1984) believes that reading is the process of reading and understanding words. Goodman (1967) pointed out that reading is a psycholinguistic guessing game, including the interactive process between language and thought. Reading means that readers use their own background and experience to focus on the subject of the article and talk to the author through text, thereby causing a collision of ideas.

\section{Three Modes of English Reading}

According to the purpose and method of reading, English reading mainly has the following three modes: 


\subsection{Top-down mode}

Top-down mode is to understand the main idea of the article from a macro and overall perspective. You don't need to read word by word, and don't pay too much attention to the details of the article. You can skip it when you encounter new words and unfamiliar grammars, as long as you can grasp the main idea of the article. It is usually used in some questions that need to answer the main idea, and it is also the reading mode that we use more in the reading part of an exam.

\subsection{The bottom-up mode}

The bottom-up mode, as the name suggests, is to process the article from the words to sentences to paragraphs for details. This is also the method that students often use in the early stages of learning texts. At the same time, the teacher should start with the pronunciation, meaning and usage of each word, to the fixed match, grammar and syntax, to the meaning of the whole sentence, and finally to elaborate on the topic of the paragraph. This reading mode is suitable for detailed reading, and we need to accurately grasp the detailed information.

\subsection{The Interaction mode}

Interaction mode, which emphasizes the combination of the above two reading modes, we can neither "carelessly" nor indulge in the details of the article during the reading process. If we blindly pursue the purpose of the article in the reading process, we will lose the pleasure of reading and the reading effect will be unsatisfactory. If we only pay attention to the details of the article, or a certain vocabulary or grammar, then our reading pressure will not only greatly increase, but also our reading efficiency will reduce.

Therefore, when we read English passage, we need to selectively adopt different reading modes according to our reading purpose and needs. Only in this way can we truly enjoy the reading process and obtain the information we need. For high school students, reading is not only for the college entrance examination, but also for cultivating and establishing the students' ability to read and process English texts. Therefore, the importance of high school English reading teaching is self-evident.

\section{Schema Theory}

The word "schema" is derived from Greek and first appeared in ancient Greek philosophy and psychology works, and now the schema theory has gotten widespread attention from scholars and now it has been widely used in teaching.

\subsection{Definition of the schema theory}

Kant first defined the term "schema" as an intermediary or bridge between knowledge and direct life experience. For example, the tiger's schema represents a knowledge rule that can help us describe the imagination about this animal: four legs, its color, body characteristics, life habits, and so on. The view of modern schema theory is: schema is a kind of cognitive structure for understanding information materials, and it plays a very active role in coordinating the process of cognition. When people face new things, they must combine their original experience with new things. When we read language materials, we can connect people's schemas with the content of the materials, and then we can understand the theme of the text. Schema theory is used for all kinds of schema knowledge to analyze and understand language materials.

\subsection{Classification of schema theory}

Language schema is a kind of language's phonetic, form, meaning and syntactic knowledge. Only by mastering this language schema and possessing basic language skills can learners code text messages. Without this language schema, an article will be like a heavenly book in front of readers, and of course the entire article cannot be understood.

Content schema is the cultural experience knowledge related to the content of the material. Sometimes readers do not lack the corresponding language foundation when reading the material, but still cannot understand the passage. This is the manifestation of the lack of content schema. Therefore, in order to truly understand the text, it is necessary to connect with 
the existing cultural background knowledge and deal with it in order to truly understand the text.

Formal schema refers to the cognition of the genre of the text. Formal schema helps readers recognize the general situation, analyze the structure and logic information, understand the author's idea, and make correct predictions and understandings.

\section{Analysis of English Reading Teaching Strategies in Senior High Schools Based on Schema}

\section{Theory}

\subsection{Strengthen the learning of language schema}

The new curriculum standard points out that about 3500 words will be used in high school. However, many teachers have found that many students in high school seldom memorize words. When encountering a new word, they will not guess the meaning of the word according to the context, and will be afraid of difficulty and give up reading. Learning new words will inevitably be boring, but without the corresponding vocabulary, how can you read the article if you are "illiterate" ? Therefore, when the teacher teaches vocabulary, to strengthen the memory of the words, they can "bring the old with the new", link the new words just learned with the vocabulary in the similar range that they have learned, and help students make sentences, and use these words to make variations. Furthermore, teachers can add some vocabulary closely related to students' life experience to increase their interest in learning English words. Teachers can also organize some vocabulary contests and fun activities to stimulate students' learning motivation, and at the same time it can help them realize the importance of developing language schemas. Only by clearing the language barrier, students can continue the reading tasks.

\subsection{Enrich students' content schema}

In traditional teaching, some teachers focus more on the teaching of vocabulary and grammar, but ignoring the teaching of related cultural background knowledge. Many students cannot find the interest and meaning of reading related articles, and the reading efficiency will be reduced. Teachers can start from two aspects: firstly, increase the input of textrelated content schemas in the classroom. For example, add the input of relevant literary works in the teaching, and teachers can use some pictures or videos to help students understand. Reading some literary works can enhance students' text information processing ability and can establish a more complete content schema. Secondly, supplement a variety of reading materials after class and select some current affairs hotspots and topics of interest to students, such as network security issues, eco-tourism, NBA stars and ball games, new energy development, environmental protection, etc.

\subsection{Meaningful guidance on formal schema}

There are many genres of reading materials for the English examination papers, including arguments, narratives, stories, and so on. If you have read more types of materials, then students will have richer forms and schemas, and they will be more confident in reading process. Teachers can show and analyze different types of articles to students in the teaching process, and teach students different reading skills. For example, when they read argumentative essays, they should pay attention to the first and last sentences and paragraphs, and teachers can guide them how to deal with detailed information when reading narrative articles. In this way, students can quickly recognize the type of passages in the exam, and then use their proficient reading methods in a targeted manner to make reading more efficient.

\section{Conclusions}

The English reading ability of senior high school students is related to the entire English learning process. The application of schema theory to high school English reading teaching is the need of teaching development. Those students who have a richer schema foundation can improve efficiency and learn to enjoy English learning. Therefore, high school English teachers should make full use of schema theory to guide students to consciously link the old and new knowledge 
and increase the training of reading topics. At the same time, teachers should guide students to input more relevant cultural background knowledge, enrich life experience, and allow students to establish active language schemas, content schemas, and formal schemas in their minds to cultivate their good reading ability.

\section{Conflicts of Interest}

The author declares no conflicts of interest regarding the publication of this paper.

\section{References}

[1] He L. (2020). Research on English Reading Teaching in Senior High Schools Based on Schema Theory. English Journal for Middle School Students, (48):10.

[2] Ministry of Education of the People's Republic of China. (2017). English Curriculum Standards for General High Schools. Beijing: People's Education Press.

[3] Li L. (2021). The Application of Schema Theory in English Reading Teaching in Senior High School. English Journal for Middle School Students, (06):3.

[4] Wang X.Y., Zhao L.J. (2021). An Experimental Research on Improving High School Students' English Reading Literacy by Reading Teaching Based on Schema Theory. Basic Foreign Language Education, 23(01):22-30.

[5] Eddie, W. (1984). Reading in the Language Classroom Teaching. London: Macmillan Publishers Limited.

[6] Goodman, K.S. (1967). Reading: A Psycholinguistics Guessing Game. Journal of the Reading Specialist, (04):126-135.

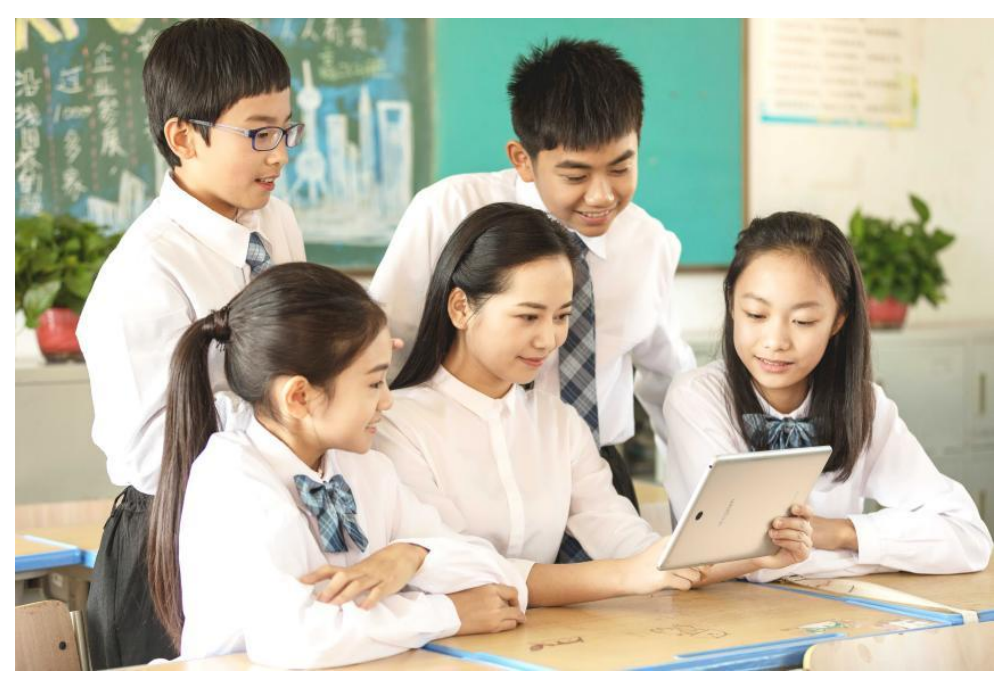

